\title{
Effect of ertugliflozin on blood pressure in patients with type 2 diabetes mellitus: a post hoc pooled analysis of randomized controlled trials
}

\author{
Jie Liu ${ }^{1 *} \mathbb{B}$, Annpey Pong ${ }^{1}$, Silvina Gallo², Amanda Darekar ${ }^{3}$ and Steven G. Terra ${ }^{4}$
}

\begin{abstract}
Background: The efficacy of ertugliflozin, a sodium-glucose cotransporter 2 inhibitor, for glycemic and blood pressure (BP) control has been demonstrated in phase 3 studies. To further evaluate the effects of ertugliflozin on BP and other hemodynamic parameters, an analysis was conducted on the pooled patient populations from these studies.

Methods: This was a post hoc analysis of data from three phase 3 studies (NCT01958671, NCT02033889, and NCT02036515) of adults with type 2 diabetes mellitus who received placebo, ertugliflozin 5 mg, or ertugliflozin 15 mg. Outcomes at 26 weeks were analyzed for the pooled population and according to relevant baseline factors, including BP.

Results: Of the 1544 patients included (placebo, $n=515$; ertugliflozin $5 \mathrm{mg}, \mathrm{n}=519$; ertugliflozin $15 \mathrm{mg}, \mathrm{n}=510$ ), most (67.4-69.0\%) had hypertension at baseline. Mean baseline BP was similar across treatment groups (placebo, 129.7/78.0 mmHg; ertugliflozin 5 mg, 131.0/78.4 mmHg; ertugliflozin 15 mg, 130.5/78.4 mmHg). At Week 26, placeboadjusted least squares (LS) mean changes (95\% confidence intervals [CI]) from baseline in systolic BP (SBP) were $-3.7 \mathrm{mmHg}(-5.1,-2.3)$ for both ertugliflozin doses. Reductions were consistent across all baseline subgroups. At Week 26, more patients with a baseline SBP $\geq 130 \mathrm{mmHg}$ had a SBP $<130 \mathrm{mmHg}$ with ertugliflozin (38.7\% both doses) than with placebo (24.0\%), and more patients with a baseline SBP $\geq 140 \mathrm{mmHg}$ attained a SBP $<140 \mathrm{mmHg}$ with ertugliflozin (59.5\% [5 mg] and 66.7\% [15 mg]) than with placebo (43.8\%). Placebo-adjusted LS mean changes $(95 \% \mathrm{Cl})$ in diastolic BP (DBP) with ertugliflozin $5 \mathrm{mg}$ and $15 \mathrm{mg}$ were $-1.8 \mathrm{mmHg}(-2.7,-0.9)$ and $-1.6 \mathrm{mmHg}$ $(-2.5,-0.7)$, respectively, and in pulse rate were -1.3 beats per minute $(\mathrm{bpm})(-2.2,-0.3)$ and $-1.5 \mathrm{bpm}(-2.5$, $-0.6)$, respectively. Greater reductions in pulse pressure, mean arterial pressure, and double product were observed with ertugliflozin than with placebo. Incidence of adverse event-related osmotic diuresis was low, but greater with ertugliflozin (2.9\% [5 mg], 2.4\% [15 mg]) than placebo (1.0\%).
\end{abstract}

Conclusion: Ertugliflozin treatment led to reductions in SBP, DBP, and pulse rate relative to placebo. Reductions in SBP were generally consistent across the subgroups evaluated.

Trial registration NCT01958671; NCT02033889; NCT02036515

Keywords: Ertugliflozin, Sodium-glucose cotransporter 2 inhibitor, Blood pressure, Systolic blood pressure, Diastolic blood pressure, Pulse rate, Hypertension, Type 2 diabetes mellitus

\footnotetext{
*Correspondence: jie.liu11@merck.com

${ }^{1}$ Merck \& Co., Inc., Kenilworth, NJ, USA

Full list of author information is available at the end of the article
} 


\section{Background}

Hypertension is a common comorbidity in patients with type 2 diabetes mellitus (T2DM) and a major risk factor for cardiovascular (CV), cerebrovascular, and renal disease [1-3]. Blood pressure (BP) control is of particular clinical significance as CV disease remains the leading cause of mortality in adults with T2DM [4]. For adults with T2DM, the American Diabetes Association advise a target systolic BP $(\mathrm{SBP})<140 \mathrm{mmHg}$ and diastolic BP $(\mathrm{DBP})<90 \mathrm{mmHg}[1]$, and the European Society of Cardiology recommend a target $\mathrm{SBP}<140 \mathrm{mmHg}$ and DBP $<80 \mathrm{mmHg}$ [5]. The American Heart Association guidelines propose a lower target of $<130 / 80 \mathrm{mmHg}$ in adults with T2DM and hypertension [3], and the European Society of Cardiology guidelines advise that if antihypertensive therapy is tolerated, achieving a $\mathrm{SBP}<130 \mathrm{mmHg}$ should be considered due to the benefits of stroke prevention. Despite these guideline recommendations, a substantial number of patients with T2DM do not achieve the recommended BP targets [6-9].

In addition to improved glycemic control, clinically relevant reductions in BP in patients with T2DM have been observed with sodium-glucose cotransporter 2 (SGLT2) inhibitor treatment [10-13]. Beneficial effects on BP were also observed in SGLT2 inhibitor CV outcomes studies [14-18].

Reductions in SBP were observed with ertugliflozin, a highly selective SGLT2 inhibitor, in the eValuation of ERTugliflozin effIcacy and Safety (VERTIS) phase 3 clinical trials program in patients with T2DM [19-23]. In order to characterize the BP-lowering effect of ertugliflozin and to examine the influence of BP-related factors, such as age, ethnicity, hypertension status, and use of antihypertensive agents on BP and other related outcomes, we conducted a post hoc analysis of pooled patient data from three placebo-controlled phase 3 clinical studies in the VERTIS program [19, 20, 23]. These studies were considered suitable for such an analysis as they included similar patient populations and had similar designs $[19,20,23]$. In addition to characterizing the BPlowering effects of ertugliflozin, we evaluated the incidence of adverse events (AEs), including events related to osmotic diuresis and hypovolemia. The proportion of patients with orthostatic changes was also analyzed. Here, we present the results of this analysis.

\section{Methods}

\section{Data sources}

Data were pooled from VERTIS MONO (protocol MK-8835-003; clinicaltrials.gov identifier NCT01958671) [23], VERTIS MET (protocol MK-8835-007; clinicaltrials. gov identifier NCT02033889) [19], and VERTIS SITA2 (protocol MK-8835-006; clinicaltrials.gov identifier
NCT02036515) [20]. All studies contributing data to this analysis were conducted in accordance with principles of Good Clinical Practice, and were approved by the appropriate institutional review boards and regulatory agencies. Informed consent was obtained from individuals in each study. The analyses in this article are based on previously conducted studies and do not involve any new studies of human patients or animal subjects performed by any of the authors. Methods and results of the three individual studies have been reported previously [19, 20, 23], and the studies are briefly described below.

\section{Patients and data sources}

Adults with T2DM according to the American Diabetes Association criteria [24] with baseline glycated hemoglobin (HbA1c) levels of $7.0 \%$ to $10.5 \%$ (inclusive) were enrolled. Key exclusion criteria included: type 1 diabetes mellitus; history of ketoacidosis; estimated glomerular filtration rate $($ eGFR $)<55 \mathrm{~mL} / \mathrm{min} / 1.73 \mathrm{~m}^{2}$ $\left(<60 \mathrm{~mL} / \mathrm{min} / 1.73 \mathrm{~m}^{2}\right.$ in VERTIS SITA2); history of a CV event within 3 months of screening; and mean value for triplicate of sitting $\mathrm{SBP}>160 \mathrm{mmHg}$ and/or $\mathrm{DBP}>90 \mathrm{mmHg}$ at any time during screening (patients receiving BP medication must have had a stable regimen for $\geq 4$ weeks prior to randomization) $[19,20,23]$.

All studies comprised a 26-week, double-blind, placebo-controlled treatment period (phase A), followed by a phase B treatment period of 26 weeks (78 weeks for VERTIS MET [19]). The primary efficacy time point of the three individual studies was Week 26; data up to this time point are included in the present analysis.

Patients were randomized 1:1:1 to placebo, ertugliflozin $5 \mathrm{mg}$, or ertugliflozin $15 \mathrm{mg}$ once daily. Patients in VERTIS MONO received no concomitant background antihyperglycemic therapy [23]; patients in VERTIS MET received concomitant metformin monotherapy ( $\geq 1500 \mathrm{mg} /$ day) [19]; and patients in VERTIS SITA2 received concomitant metformin ( $\geq 1500 \mathrm{mg} /$ day) and sitagliptin (100 mg/day) [20].

\section{Endpoints and assessments}

The efficacy endpoints reported for this post hoc analysis were the change from baseline in SBP, DBP, pulse rate, pulse pressure (SBP-DBP), mean arterial pressure (calculated as $2 / 3 \mathrm{DBP}+1 / 2 \mathrm{SBP}$ ) and double product $(\mathrm{SBP} \times$ pulse rate $)$ at Week 26 . The percentage of patients with SBP < $130 \mathrm{mmHg}$ (among patients with baseline SBP $\geq 130 \mathrm{mmHg}$ ) and SBP $<140 \mathrm{mmHg}$ (among patients with baseline $\mathrm{SBP} \geq 140 \mathrm{mmHg}$ ) at Week 26 were also reported. Use of antihypertensive therapy at baseline and at Week 26 was also reported.

In each study, sitting BP was measured in triplicate with an automated oscillometric BP measuring device, 
with measurements after at least 5 min of rest. Patients were advised to avoid nicotine-containing products and/ or ingesting caffeine for at least $30 \mathrm{~min}$ preceding the measurements.

A summary of the incidence of AEs is reported, as well as the incidences of orthostatic change in SBP and DBP, and the incidence of AEs related to osmotic diuresis and hypovolemia. Orthostatic change in SBP and DBP was defined as a reduction (after 1 and/or 3 min of standing from the supine position) of $\geq 20 \mathrm{mmHg}$ or $\geq 10 \mathrm{mmHg}$, respectively.

\section{Statistical methods}

The primary efficacy analyses were conducted on the population of all randomized, treated patients who had at least one measurement of the analysis endpoint at or after baseline. The safety analysis was conducted on all randomized, treated patients. All analyses (efficacy and safety) included data obtained after the initiation of glycemic rescue therapy. As this was a post hoc exploratory analysis, no pre-specified hypotheses were tested, and $p$ values are not presented (except for assessing the significance of correlation coefficients).

The primary analysis of changes from baseline in sitting SBP, DBP, pulse rate, pulse pressure, mean arterial pressure, and double product used a longitudinal data analysis model with fixed effects to adjust for treatment, time, study, baseline eGFR, and the interaction of time by treatment [25]. Time was treated as a categorical variable. No imputation of missing data was performed. The differences in least squares (LS) means with $95 \%$ confidence interval $(\mathrm{CI})$ for comparisons of ertugliflozin $5 \mathrm{mg}$ or $15 \mathrm{mg}$ versus placebo were calculated.

The percentage of patients at Week 26 with $\mathrm{SBP}<130 \mathrm{mmHg}$ (among patients with $\mathrm{SBP} \geq 130 \mathrm{mmHg}$ at baseline) and $<140 \mathrm{mmHg}$ (among patients with a baseline $\mathrm{SBP} \geq 140 \mathrm{mmHg}$ ) compared with placebo were analyzed using the Miettinen and Nurminen method [26]; patients with missing data at Week 26 were considered non-responders.

The following subgroups were analyzed for change from baseline in SBP using a repeated measures analysis of covariance model: age ( $<65$ or $\geq 65$ years), sex, race (White, Black, Asian, or other), baseline body mass index (BMI; above or below median $\left[30.8 \mathrm{~kg} / \mathrm{m}^{2}\right]$ ), baseline eGFR $\left(<90\right.$ or $\left.\geq 90 \mathrm{~mL} / \mathrm{min} / 1.73 \mathrm{~m}^{2}\right)$, baseline SBP $(\leq 130$, or $>130-140$, or $>140 \mathrm{mmHg})$, baseline antihypertensive therapy use (diuretic and/or renin-angiotensin-aldosterone system [RAAS] blocker use), and baseline HbA1c level $(<8.0 \%, 8.0 \%$ to $<9.0 \%$, or $\geq 9.0 \%)$. The analysis of covariance model was adjusted for treatment, time, study, baseline eGFR, baseline value of the response variable, and the interaction of time by treatment. The population for subgroup analyses contained all randomized, treated patients who had a baseline SBP measurement and at least one SBP measurement after baseline.

The number and percentage of patients with antihypertensive therapy use at baseline and at Week 26 are presented by treatment group.

Scatter plots of individual participant data presented change from baseline in SBP at Week 26 versus change in HbA1c at Week 26 and change from baseline in body weight at Week 26. Pearson correlation coefficients were used to test the linear relationship between the variables.

\section{Results}

\section{Patient population}

A total of 1544 randomized patients were included in the analyses (461 from VERTIS MONO, 621 from VERTIS MET, and 462 from VERTIS SITA2). Of these, 515 patients received placebo, 519 ertugliflozin $5 \mathrm{mg}$, and 510 ertugliflozin $15 \mathrm{mg}$. Patient demographic and baseline clinical characteristics were balanced across treatment groups (Table 1). At baseline, 67.8\%, 69.0\%, and $67.4 \%$ of patients had a history of hypertension in the placebo, ertugliflozin $5 \mathrm{mg}$, and ertugliflozin $15 \mathrm{mg}$ groups, respectively. The corresponding mean SBP/DBP values at baseline were $129.7 / 78.0 \mathrm{mmHg}, 131.0 / 78.4 \mathrm{mmHg}$, and $130.5 / 78.4 \mathrm{mmHg}$, respectively. At baseline, $60.8 \%$, $62.8 \%$, and $60.4 \%$ of patients were using antihypertensive therapies in the placebo, ertugliflozin $5 \mathrm{mg}$, and ertugliflozin $15 \mathrm{mg}$ groups, respectively. The majority of these were RAAS blockers, which were used in $54.8 \%, 56.5 \%$, and $54.5 \%$ of patients at baseline in the placebo, ertugliflozin $5 \mathrm{mg}$ and ertugliflozin $15 \mathrm{mg}$ groups, respectively.

\section{$\mathrm{BP}$ and pulse rate}

Treatment with ertugliflozin $5 \mathrm{mg}$ and $15 \mathrm{mg}$ resulted in a greater reduction from baseline in SBP at Week 26 compared with placebo (placebo-adjusted LS mean changes [95\% CI] from baseline in SBP were $-3.7 \mathrm{mmHg}[-5.1$, -2.3] for both ertugliflozin doses; Fig. 1a).

The proportion of patients with $\mathrm{SBP} \geq 130 \mathrm{mmHg}$ at baseline who subsequently achieved $\mathrm{SBP}<130 \mathrm{mmHg}$ at Week 26 was higher in the ertugliflozin $5 \mathrm{mg}$ and $15 \mathrm{mg}$ groups compared with the placebo group (37.8\% with both ertugliflozin doses versus $24.0 \%$ with placebo; Fig. 1b). At Week $26,59.5 \%$ and $66.7 \%$ of patients with baseline $\mathrm{SBP} \geq 140 \mathrm{mmHg}$ achieved a $\mathrm{SBP}<140 \mathrm{mmHg}$ in the ertugliflozin $5 \mathrm{mg}$ and $15 \mathrm{mg}$ groups, respectively, versus $43.8 \%$ of patients in the placebo group (Fig. 1b).

Patients with a high baseline SBP $(>130$ to $\leq 140 \mathrm{mmHg}$ and $>140 \mathrm{mmHg}$ ) exhibited larger LS mean reductions from baseline in SBP compared with patients with low baseline SBP values $(\leq 130 \mathrm{mmHg})$ 
Table 1 Baseline demographics and clinical characteristics

\begin{tabular}{|c|c|c|c|}
\hline & $\begin{array}{l}\text { Placebo } \\
(n=515)\end{array}$ & $\begin{array}{l}\text { Ertugliflozin } 5 \mathrm{mg} \\
(\mathrm{n}=519)\end{array}$ & $\begin{array}{l}\text { Ertugliflozin } 15 \mathrm{mg} \\
(\mathrm{n}=510)\end{array}$ \\
\hline Age, years & $56.9(9.6)$ & $57.4(9.6)$ & $57.5(9.7)$ \\
\hline Male, n (\%) & $280(54.4)$ & $267(51.4)$ & $265(52.0)$ \\
\hline $\mathrm{BMl}, \mathrm{kg} / \mathrm{m}^{2}$ & $31.3(6.0)$ & $31.6(6.0)$ & $31.5(5.4)$ \\
\hline \multicolumn{4}{|l|}{ Race, n (\%) } \\
\hline White & $378(73.4)$ & $382(73.6)$ & $374(73.3)$ \\
\hline Asian & $79(15.3)$ & $77(14.8)$ & $77(15.1)$ \\
\hline Black or African American & $31(6.0)$ & $34(6.6)$ & $37(7.3)$ \\
\hline Other & $27(5.2)$ & $26(5.0)$ & $22(4.3)$ \\
\hline Duration of T2DM, years & $7.4(5.9)$ & $7.6(6.1)$ & $7.6(5.7)$ \\
\hline $\mathrm{HbA} 1 \mathrm{c}, \%^{\mathrm{a}}$ & $8.1(0.9)$ & $8.1(0.9)$ & $8.2(1.0)$ \\
\hline $\mathrm{eGFR}, \mathrm{mL} / \mathrm{min} / 1.73 \mathrm{~m}^{2}$ & $89.5(19.1)$ & $88.2(17.7)$ & $89.0(18.5)$ \\
\hline Medical history of hypertension, n (\%) & $349(67.8)$ & $358(69.0)$ & $344(67.4)$ \\
\hline \multicolumn{4}{|l|}{ Sitting SBP, mmHg ${ }^{b}$} \\
\hline Mean (SD) & $129.7(14.5)$ & $131.0(13.3)$ & $130.5(13.0)$ \\
\hline$\leq 130, \mathrm{n}(\%)$ & $268(53.2)$ & $244(47.7)$ & $249(49.6)$ \\
\hline$>130, n(\%)$ & $236(46.8)$ & $268(52.3)$ & $253(50.4)$ \\
\hline$\leq 140, \mathrm{n}(\%)$ & $388(77.0)$ & $392(76.6)$ & $383(76.3)$ \\
\hline$>140, n(\%)$ & $116(23.0)$ & $120(23.4)$ & $119(23.7)$ \\
\hline Sitting DBP, mmHg ${ }^{b}$ & $78.0(7.5)$ & $78.4(7.9)$ & $78.4(7.5)$ \\
\hline Pulse rate, bpm & $72.6(9.2)$ & $72.8(10.0)$ & $72.6(9.3)$ \\
\hline Microvascular diseasec, n (\%) & $85(16.5)$ & $90(17.3)$ & $86(16.9)$ \\
\hline \multicolumn{4}{|l|}{ Antihypertensive therapy used, $\mathrm{n}(\%)^{d}$} \\
\hline Any & $313(60.8)$ & $326(62.8)$ & $308(60.4)$ \\
\hline Diuretics & $31(6.0)$ & $41(7.9)$ & $38(7.5)$ \\
\hline RAAS blockers & $282(54.8)$ & $293(56.5)$ & $278(54.5)$ \\
\hline$\beta$ blockers & $127(24.7)$ & $113(21.8)$ & $105(20.6)$ \\
\hline Calcium channel blockers & $12(2.3)$ & $10(1.9)$ & $13(2.6)$ \\
\hline
\end{tabular}

Data presented as mean (SD), unless otherwise specified

$B M I$ body mass index, bpm beats per minute, $D B P$ diastolic blood pressure, eGFR estimated glomerular filtration rate, $H b A 1 c$ glycated hemoglobin, $R A A S$ reninangiotensin-aldosterone system, SBP systolic blood pressure, SD standard deviation, T2DM type 2 diabetes mellitus

a Number of patients with data: 512 (placebo), 515 (ertugliflozin $5 \mathrm{mg}$ ), 504 (ertugliflozin $15 \mathrm{mg}$ )

b Number of patients with data: 504 (placebo), 512 (ertugliflozin $5 \mathrm{mg}$ ), 502 (ertugliflozin $15 \mathrm{mg}$ )

c Included preferred terms defined by a sponsor-generated custom Medical Dictionary for Regulatory Activities (MeDRA) query reported as medical history related to diabetic microvascular complications (Additional file 1)

d Some patients took more than one hypertension therapy at baseline

across treatment groups. Furthermore, larger LS mean reductions from baseline in SBP were demonstrated in patients receiving ertugliflozin compared with placebo in all baseline SBP subgroups (Fig. 2a). In general, LS mean reductions in SBP from baseline were greater in the ertugliflozin groups than in the placebo group across all subgroups by baseline SBP (Fig. 2a). In patients with baseline antihypertensive therapy or RAAS blocker use, both ertugliflozin $5 \mathrm{mg}$ and $15 \mathrm{mg}$ led to marked reductions in SBP compared with placebo (Fig. 2b). Reductions in SBP were not meaningfully different in the ertugliflozin groups compared with placebo in patients taking a diuretic at baseline. However, the low number of patients in each treatment group within this subgroup resulted in a reduced precision of the estimates (Fig. 2b). Ertugliflozin resulted in placebo-adjusted SBP reductions from baseline in the patient subgroups, including patients with an eGFR $<90 \mathrm{~mL} / \mathrm{min} / 1.73 \mathrm{~m}^{2}$ (Fig. 3).

No correlations between changes from baseline in SBP and HbA1c at Week 26 were observed in the placebo or ertugliflozin groups (Pearson correlation coefficient $\mathrm{p}$ values $>0.05$; Fig. 4a). Across all treatment groups, there was a significant correlation between the change 

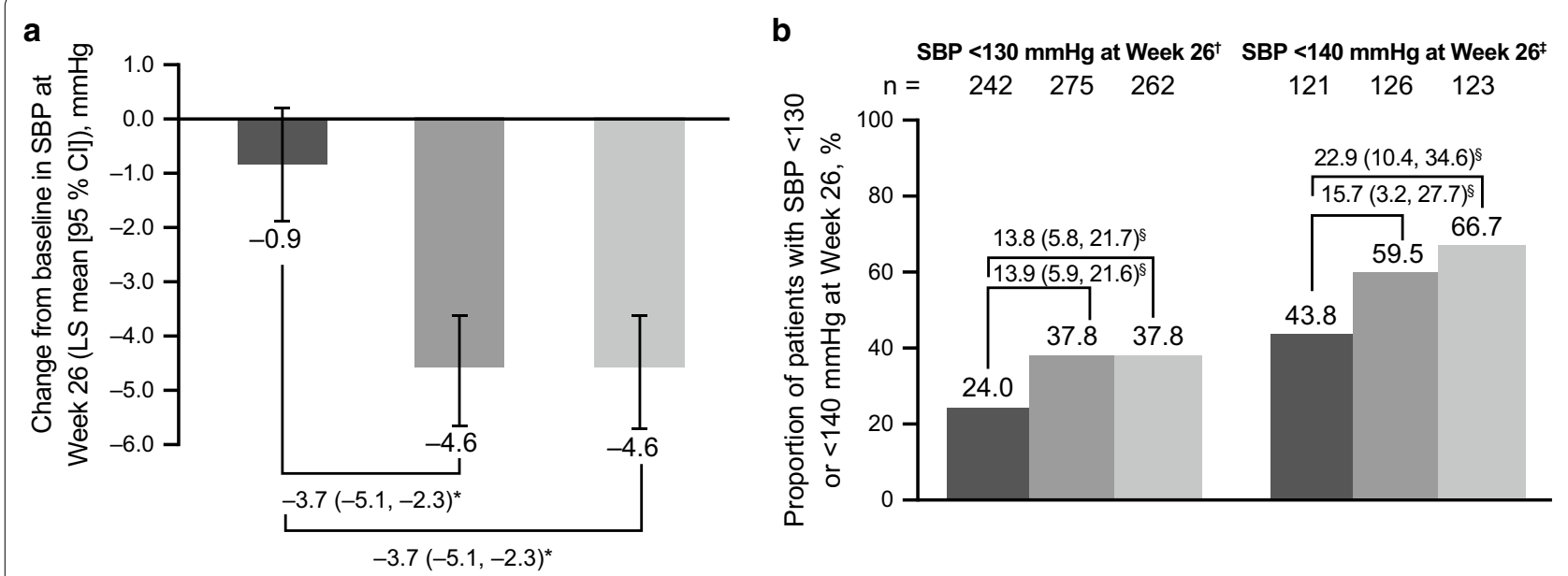

Placebo $(n=497) \quad$ Ertugliflozin $5 \mathrm{mg}(\mathrm{n}=506) \quad$ Ertugliflozin $15 \mathrm{mg}(\mathrm{n}=495)$

Fig. 1 Change from baseline in systolic blood pressure (SBP). Change from baseline in SBP at Week 26 (a) and proportion of patients with $\mathrm{SBP}<130 \mathrm{mmHg}$ and $<140 \mathrm{mmHg}$ at Week $26(\mathbf{b})$. Cl confidence interval; $L S$ least squares. *Placebo-adjusted difference in LS mean (95\% CI). ${ }^{\dagger} \mathrm{O}$ patients with baseline SBP of $\geq 130 \mathrm{mmHg}$. ${ }^{\ddagger} \mathrm{Of}$ patients with baseline SBP of $\geq 140 \mathrm{mmHg}$. ${ }^{5}$ Difference in response rate $(95 \% \mathrm{Cl})$

from baseline in SBP and body weight at Week 26 (Pearson correlation coefficient p values < 0.05; Fig. 4b).

Both ertugliflozin $5 \mathrm{mg}$ and $15 \mathrm{mg}$ resulted in a greater reduction from baseline in DBP and pulse rate compared with placebo at Week 26 (Fig. 5a, b).

\section{Other BP parameters and antihypertensive therapy use}

Compared with placebo, greater reductions from baseline in pulse pressure, mean arterial pressure, and double product were observed in both the ertugliflozin $5 \mathrm{mg}$ and $15 \mathrm{mg}$ groups (Table 2 ).

There was no meaningful change from baseline in the use of antihypertensive therapies across groups at Week 26 (Table 3).

\section{Safety}

The incidence of AEs was similar across treatment groups (Table 4). The incidence of serious AEs and AEs that led to discontinuation of study medication was low and not meaningfully different between groups. The incidence of hypovolemia AEs, including hypotension, was low across the treatment groups. The incidence of AEs of osmotic diuresis was low across the treatment groups, but higher in the ertugliflozin groups relative to the placebo group. The proportions of patients who met the pre-specified definition for orthostatic changes in SBP and DBP were similar between treatment groups at baseline, Week 6, and Week 26 (Table 4).

\section{Discussion}

In this post hoc analysis of data from three phase 3 randomized, placebo-controlled studies, ertugliflozin $5 \mathrm{mg}$ and $15 \mathrm{mg}$ resulted in greater reductions in SBP after 26 weeks of treatment compared with placebo. These reductions were observed across the subgroups analyzed. Greater mean reductions in DBP and pulse rate were also observed with ertugliflozin compared with placebo. The effects on BP in this pooled analysis are generally consistent with results from studies with other SGLT2 inhibitors $[11,12,27-31]$. Greater reductions in BP with ertugliflozin relative to placebo over a longer treatment period of 104 weeks have also been reported [32]. In addition, a meta-analysis of SGLT2 inhibitor effects on BP reported significant placebo-adjusted changes (weighted mean difference) of $-2.5 \mathrm{mmHg}$ and $-1.5 \mathrm{mmHg}$ in SBP and DBP, respectively [33]. Reductions in SBP with ertugliflozin were also observed in active comparator studies [21, 34]. For example, compared with glimepiride, ertugliflozin lowered SBP by $-3.2 \mathrm{mmHg}$ (ertugliflozin $5 \mathrm{mg}$ ) and $-4.8 \mathrm{mmHg}$ (ertugliflozin $15 \mathrm{mg}$ ) at Week 52 [34]. Similarly, the VERTIS FACTORIAL study reported favorable changes in SBP at Week 26 in the ertugliflozin treatment groups $(-3.9 \mathrm{mmHg}$ [ertugliflozin $5 \mathrm{mg}$ ] and $-3.7 \mathrm{mmHg}$ [ertugliflozin $15 \mathrm{mg}$ ]) compared with sitagliptin $100 \mathrm{mg}(-0.7 \mathrm{mmHg})$.

The change from baseline in placebo-adjusted, clinic-measured SBP was also similar to the lowering of SBP observed with ertugliflozin in a study that utilized 24-hour ambulatory BP monitoring (-3.0 to $-4.0 \mathrm{mmHg}$ ) [35], and in a systematic review and 


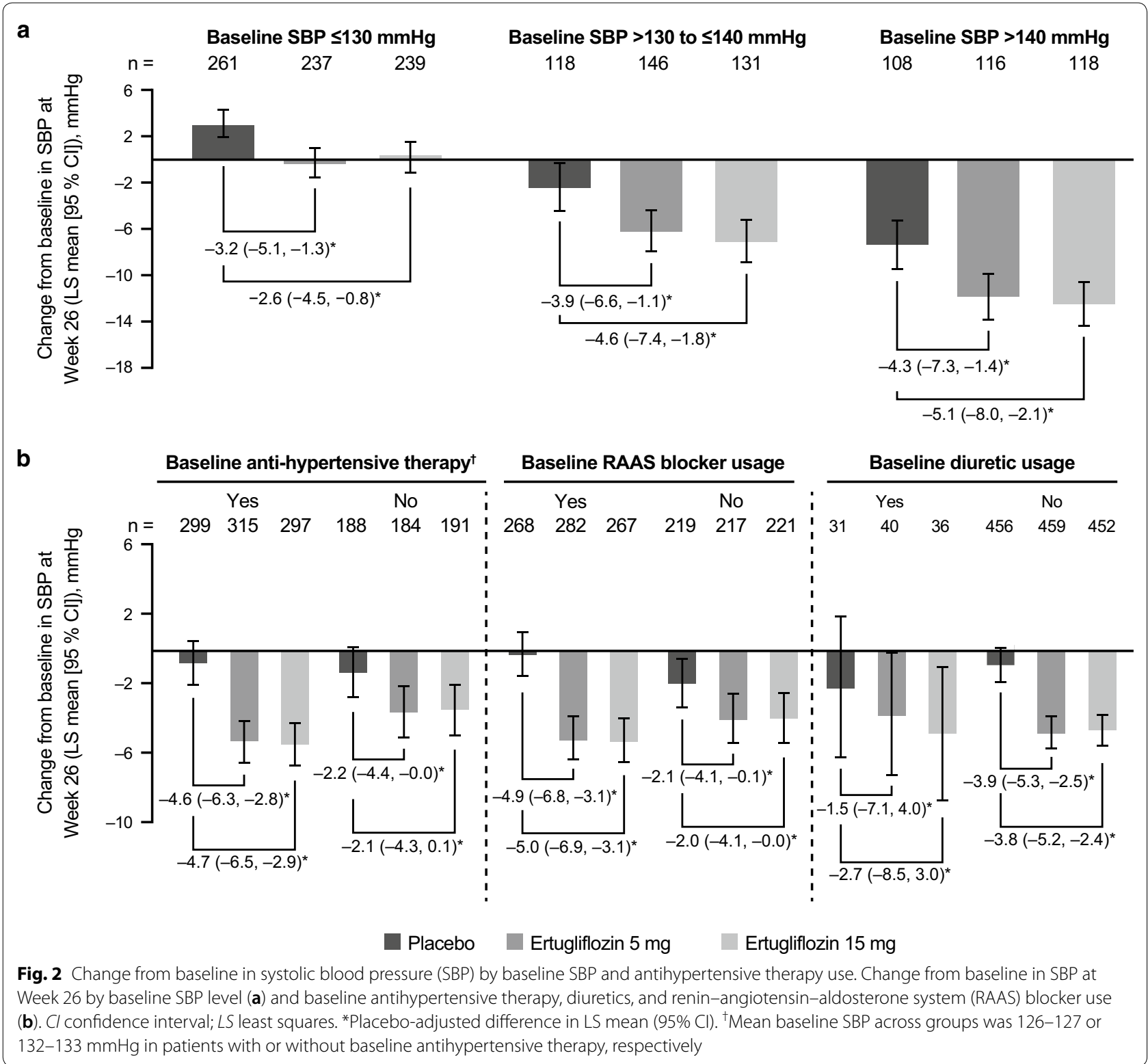

meta-analysis of SGLT2 inhibitor effects on 24-h ambulatory SBP $(-3.8 \mathrm{mmHg})$ [36].

In the current study, greater reductions in SBP in all treatment groups (ertugliflozin and placebo groups) were seen in patients with higher versus lower baseline SBP. Furthermore, patients receiving ertugliflozin were more likely to achieve guideline-recommended SBP goals at Week 26 than patients receiving placebo. This study and many others have shown the benefits of ertugliflozin and other SGLT2 inhibitors not only on glycemic control but also on BP reduction [19-22, 29, 30, 34]. Lowering elevated $\mathrm{BP}$ to the guideline-recommended targets in adults with T2DM is associated with reductions in macrovascular and microvascular complications, and death [5].

Ertugliflozin reduced SBP relative to placebo in patients receiving baseline standard of care antihypertensive therapy, including in patients using RAAS inhibitors. RAAS activity, which is a determining factor of BP, may be reduced in response to SGLT2 inhibition, mediating an increase in sodium delivery to the macula densa. However, the mechanism by which ertugliflozin reduces BP is likely to be multifactorial [36]. Changes from baseline in SBP did not correlate with changes from baseline in HbA1c in this analysis. This suggests that glycosuria (and therefore osmotic diuresis) is not 


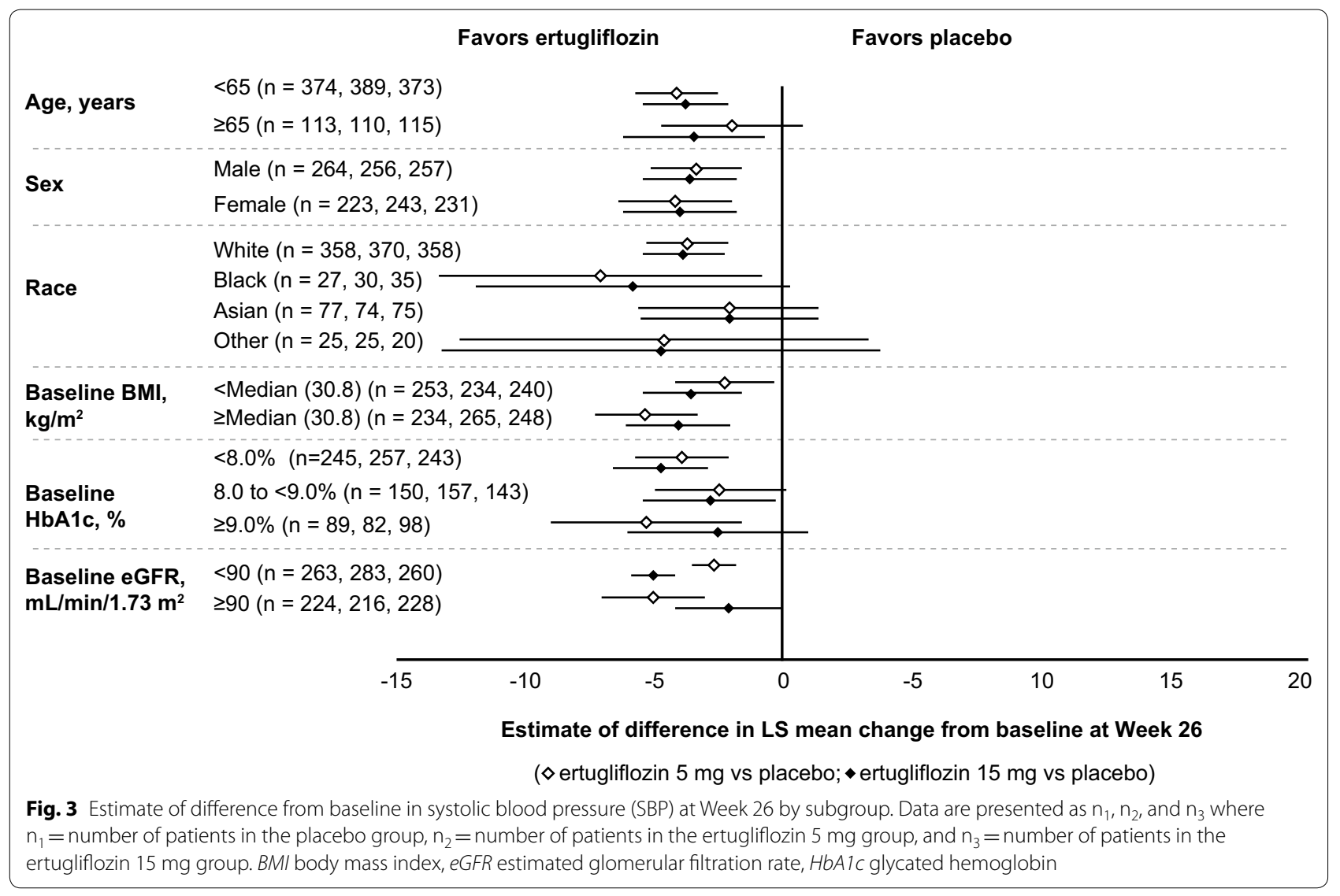

the sole mechanism accounting for the $\mathrm{BP}$ reductions reported here, a finding also suggested in studies with other SGLT2 inhibitors [11-13, 37]. Alternative pathways may account for the BP-lowering effects reported with ertugliflozin and other SGLT2 inhibitors, such as reductions in arterial stiffness and weight loss [10, 38]. In keeping with this, changes from baseline in SBP did correlate with changes from baseline in body weight in both placebo and ertugliflozin groups in this analysis. Other studies have also shown that reductions in body weight were associated with reductions in arterial stiffness and BP [38]. Treatment with SGLT2 inhibitors can alter body composition by reducing total body fat with minimal changes to lean muscle; reduction in body fat has been suggested as an additional mechanism by which SGLT2 inhibitors lower BP [36]. However, a rodent model of an SGLT2 inhibitor (empagliflozin) reported that reductions in arterial stiffness were not associated with improvements in BP [39]. Furthermore, studies of ertugliflozin have demonstrated that the reductions in SBP from baseline are observed early, by Week 12 to Week 18, and are then maintained, whereas placebo-adjusted reductions in weight from baseline plateau at the later time point of 26 weeks [20, 34], suggesting that factors beyond weight loss contribute to BP lowering.

The reductions in pulse pressure, mean arterial pressure, and double product reported here are also consistent with studies in other SGLT2 inhibitors [11, 40]. Reductions in pulse and mean arterial pressure may lead to beneficial effects on arterial stiffness and cardiac workload [41]. Despite the natriuretic and volume depletion effects of ertugliflozin, pulse rate was reduced compared with placebo. This suggests autonomic nervous system regulation with ertugliflozin, a hypothesis speculated in response to similar findings with other SGLT2 inhibitors [10].

Improvements in composite $\mathrm{CV}$ outcomes have now been demonstrated with three SGLT2 inhibitors [14, 15, 18]. Although the mechanisms through which SGLT2 inhibitors confer the observed CV benefits are not clear, the BP-lowering effects of SGLT2 inhibitors may be a relevant factor. Control of $\mathrm{BP}$ has been shown to reduce the excess risk of CV outcomes (death, stroke, myocardial infarction, and hospitalization for heart failure) in patients with T2DM [42]. The long-term effects of ertugliflozin on $\mathrm{CV}$ outcomes are being assessed in the VERTIS Cardiovascular Outcomes study (VERTIS CV; 

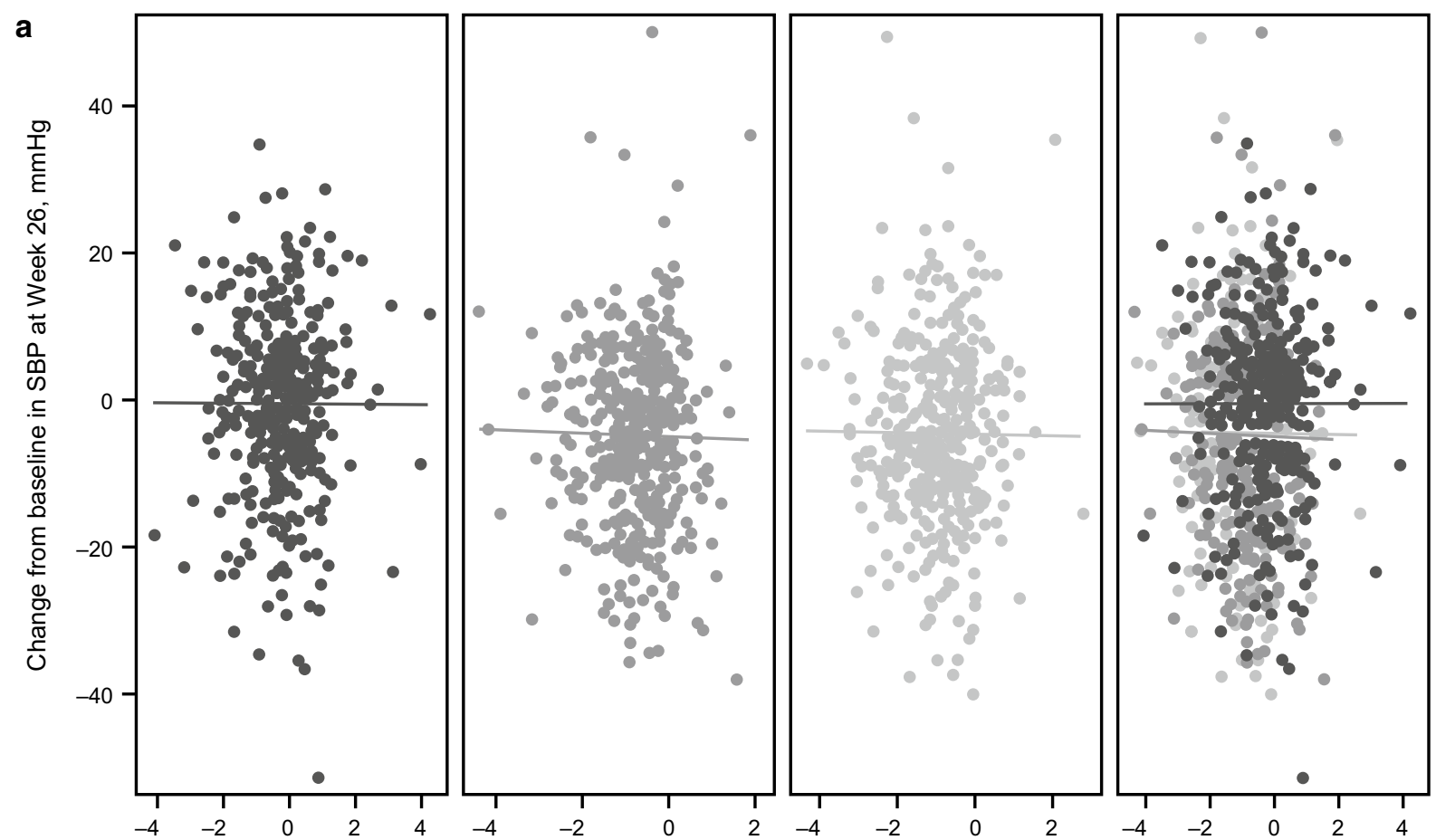

Change from baseline in HbA1c at Week 26, \%
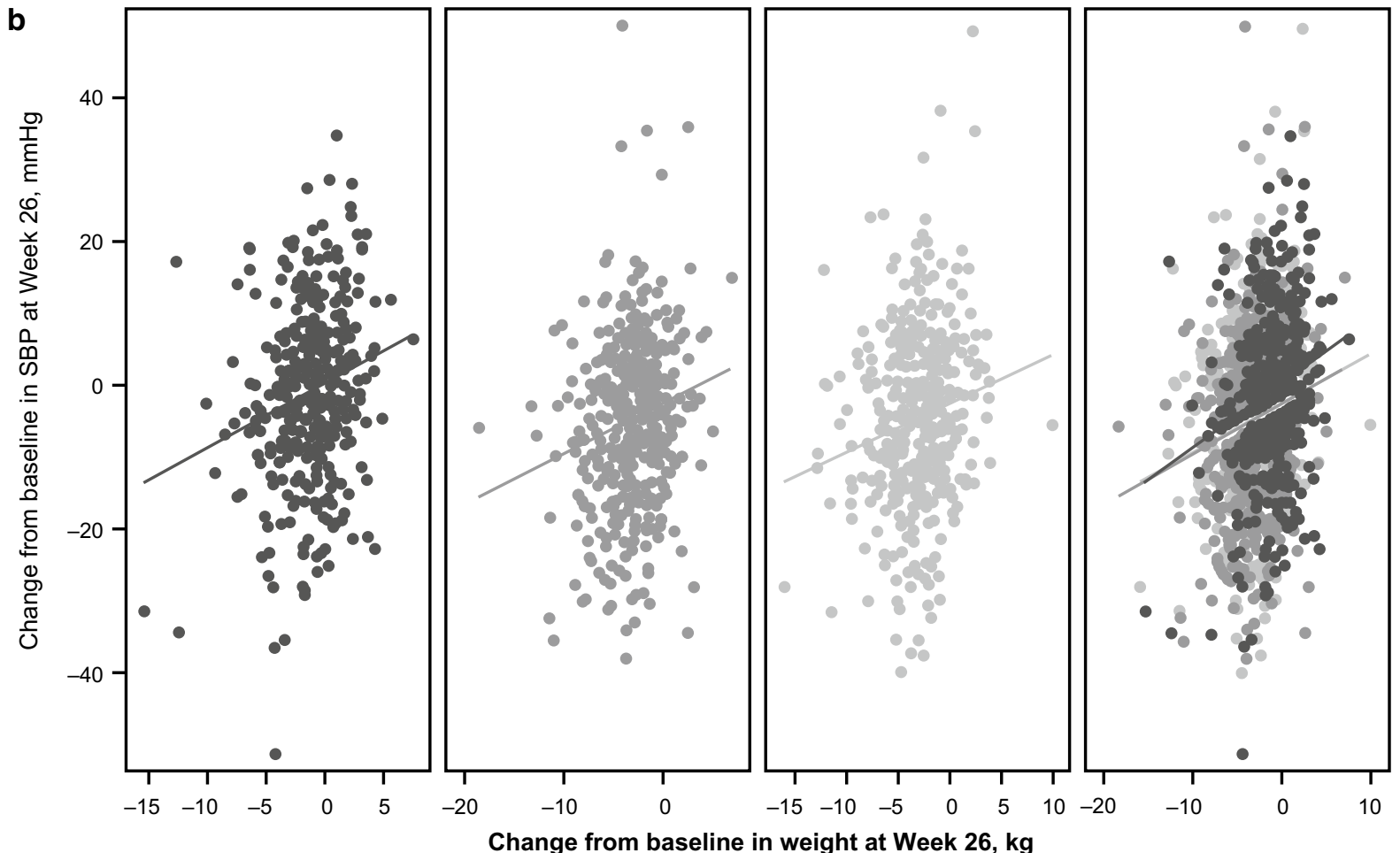

Planned Treatment:

Ertugliflozin $15 \mathrm{mg}$

Ertugliflozin $5 \mathrm{mg}$

Placebo

Fig. 4 Correlation between systolic blood pressure (SBP) and glycated hemoglobin (HbA1c) and body weight. Change from baseline in SBP at Week 26 versus change from baseline in HbA1c at Week 26 (a) and change from baseline in body weight at Week 26 (b). HbA1c glycated hemoglobin 

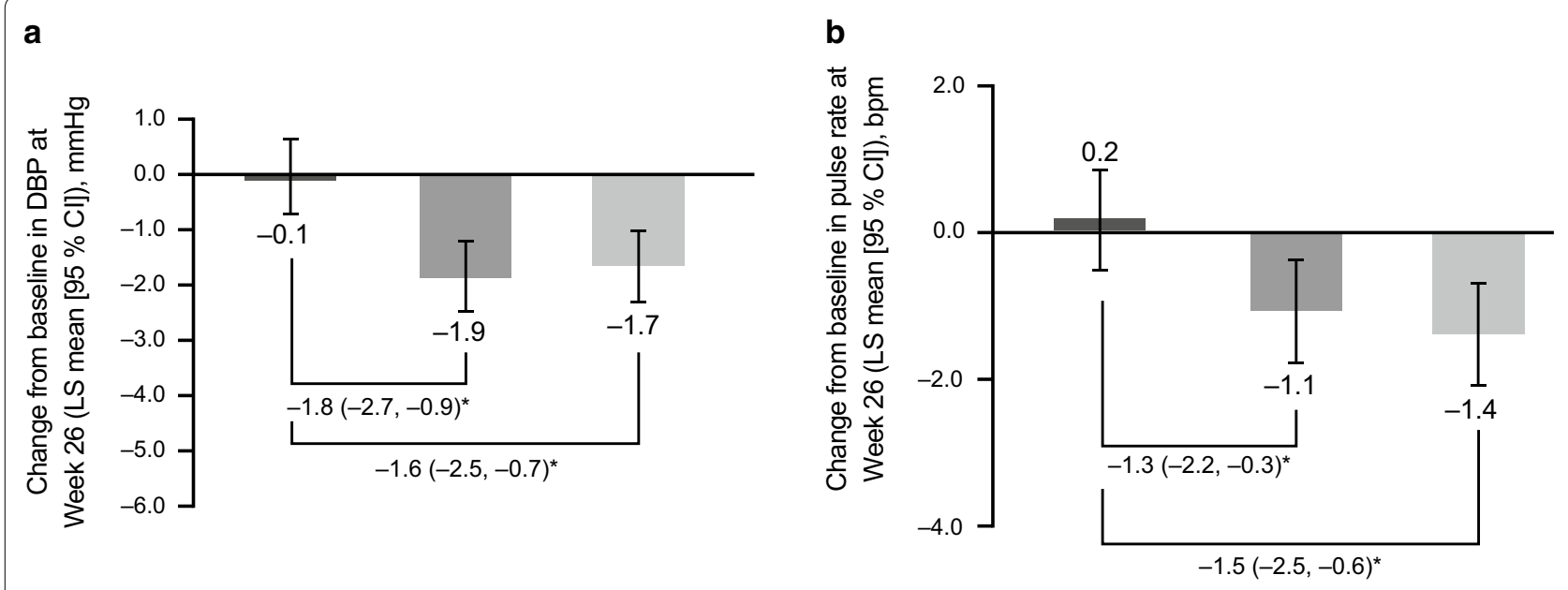

Placebo $(n=497) \quad$ Ertugliflozin $5 \mathrm{mg}(\mathrm{n}=506) \quad$ Ertugliflozin $15 \mathrm{mg}(\mathrm{n}=495)$

Fig. 5 Change from baseline in sitting diastolic blood pressure (DBP) and pulse rate at Week 26. Change from baseline in sitting DBP at Week 26 (a) and change from baseline in sitting pulse rate at Week 26 (b). Cl confidence interval, LS least squares. *Placebo-adjusted difference in LS mean $(95 \% \mathrm{Cl})$

Table 2 Change from baseline in other blood pressure parameters at Week 26

\begin{tabular}{|c|c|c|c|}
\hline & Placebo $(n=504)$ & Ertugliflozin $5 \mathrm{mg}(\mathrm{n}=519)$ & Ertugliflozin $15 \mathrm{mg}(\mathrm{n}=510)$ \\
\hline \multicolumn{4}{|l|}{ Pulse pressure, $\mathrm{mmHg}^{\mathrm{a}}$} \\
\hline Baseline mean $(S D)^{b}$ & $51.8(12.1)$ & $52.5(11.3)$ & $52.1(11.2)$ \\
\hline LS mean change from baseline (95\% Cl) & $-0.8(-1.7,0.0)$ & $-2.7(-3.5,-1.9)$ & $-2.9(-3.8,-2.1)$ \\
\hline Placebo-adjusted LS mean change from baseline ( $95 \%$ CI) & - & $-1.9(-3.0,-0.8)$ & $-2.1(-3.3,-1.0)$ \\
\hline \multicolumn{4}{|l|}{ Mean arterial pressure, $\mathrm{mmHg}^{\mathrm{a}}$} \\
\hline Baseline mean (SD) ${ }^{b}$ & $95.2(8.7)$ & $96.0(8.5)$ & $95.8(8.1)$ \\
\hline LS mean change from baseline ( $95 \% \mathrm{Cl}$ ) & $-0.3(-1.0,0.4)$ & $-2.8(-3.4,-2.1)$ & $-2.65(-3.3,-2.0)$ \\
\hline Placebo-adjusted LS mean change from baseline ( $95 \%$ Cl) & - & $-2.4(-3.4,-1.5)$ & $-2.3(-3.2,-1.4)$ \\
\hline \multicolumn{4}{|l|}{ Double product, $\mathrm{mmHg} \times \mathrm{bpm}^{\mathrm{a}}$} \\
\hline Baseline mean $(S D)^{c}$ & $9409.2(1536.9)$ & $9544.7(1668.6)$ & $9480.5(1571.1)$ \\
\hline LS mean change from baseline (95\% Cl) & $-44.0(-161.7,73.7)$ & $-479.9(-594.5,-365.3)$ & $-514.1(-630.8,-397.4)$ \\
\hline Placebo-adjusted LS mean change from baseline (95\% Cl) & - & $-435.9(-593.6,-278.2)$ & $-470.0(-629.3,-310.8)$ \\
\hline
\end{tabular}

bpm beats per minute, $\mathrm{Cl}$ confidence interval, $L S$ least squares

a Number of patients with data at Week 26: 497 (placebo), 506 (ertugliflozin $5 \mathrm{mg}$ ), 495 (ertugliflozin $15 \mathrm{mg}$ )

b Number of patients with data: 504 (placebo), 512 (ertugliflozin $5 \mathrm{mg}$ ), 502 (ertugliflozin $15 \mathrm{mg}$ )

c Number of patients with data: 504 (placebo), 512 (ertugliflozin 5 mg), 501 (ertugliflozin 15 mg)

NCT01986881), a randomized, double-blind, placebocontrolled study in patients with T2DM and established atherosclerotic $\mathrm{CV}$ disease [43].

In this analysis, both doses of ertugliflozin were generally well tolerated, with an overall safety profile similar to placebo. It has been suggested that treatment with SGLT2 inhibitors may contribute to diuresis-induced hypovolemia [11, 12, 44, 45], and it could be speculated that this might add to risks from the use of antihypertensive therapies in this patient population. While the use of some BP-lowering agents in patients with T2DM is associated with orthostatic hypotension [46], BP reductions in the ertugliflozin groups were not accompanied by an increase from baseline in the incidence of orthostatic changes in SBP and DBP. The incidence of AEs related to osmotic diuresis was higher in the ertugliflozin groups compared with placebo as expected in this class. Considering that baseline diuretic use was low and balanced among treatment groups $(6.8 \%, 7.9 \%$, and $7.5 \%$ for placebo, ertugliflozin $5 \mathrm{mg}$, and ertugliflozin $15 \mathrm{mg}$, 
Table 3 Antihypertensive therapy use at baseline and Week 26

\begin{tabular}{|c|c|c|c|}
\hline Time point & Placebo & $\begin{array}{l}\text { Ertugliflozin } \\
5 \mathrm{mg}\end{array}$ & $\begin{array}{l}\text { Ertugliflozin } \\
15 \mathrm{mg}\end{array}$ \\
\hline \multicolumn{4}{|c|}{ Patients with one or more antihypertensive therapies } \\
\hline Baseline $^{a}$ & $337(65.4)$ & $353(68.0)$ & $336(65.9)$ \\
\hline Week $26^{b}$ & $316(66.8)$ & $344(69.5)$ & $318(67.5)$ \\
\hline \multicolumn{4}{|c|}{ RAAS blockers } \\
\hline Baseline $^{a}$ & $292(56.7)$ & $306(59.0)$ & $289(56.7)$ \\
\hline Week 26 ${ }^{\mathrm{b}}$ & $278(58.8)$ & $298(60.2)$ & $271(57.5)$ \\
\hline \multicolumn{4}{|l|}{$\beta$ blockers } \\
\hline Baseline $^{a}$ & $120(23.3)$ & $104(20.0)$ & $98(19.2)$ \\
\hline Week $26^{\mathrm{b}}$ & $113(23.9)$ & $101(20.4)$ & $96(20.4)$ \\
\hline \multicolumn{4}{|c|}{ Calcium channel blockers } \\
\hline Baseline $^{a}$ & $94(18.3)$ & $91(17.5)$ & $116(22.7)$ \\
\hline Week $26^{\mathrm{b}}$ & 88 (18.6) & $93(18.8)$ & $108(22.9)$ \\
\hline \multicolumn{4}{|l|}{ Diuretics } \\
\hline Baseline $^{a}$ & $106(20.6)$ & $112(21.6)$ & $104(20.4)$ \\
\hline Week 26 & 99 (20.9) & $106(21.4)$ & $98(20.8)$ \\
\hline \multicolumn{4}{|c|}{ Other antihypertensive therapy } \\
\hline Baseline $^{a}$ & $22(4.3)$ & $18(3.5)$ & $18(3.5)$ \\
\hline Week $26^{\mathrm{b}}$ & $22(4.7)$ & $18(3.6)$ & $18(3.8)$ \\
\hline
\end{tabular}

Every patient is counted a single time for each applicable specific medication. A patient with multiple medications within a medication category is counted a single time for that category. Data presented as number of patients (\%)

RAAS renin-angiotensin-aldosterone system

a Number of patients with data: 515 (placebo), 519 (ertugliflozin $5 \mathrm{mg}$ ), and 510 (ertugliflozin $15 \mathrm{mg}$ )

${ }^{b}$ Number of patients with data: 473 (placebo), 495 (ertugliflozin $5 \mathrm{mg}$ ), and 471 (ertugliflozin $15 \mathrm{mg}$ ) respectively), the higher incidence of AEs related to osmotic diuresis observed in the ertugliflozin groups is likely due to ertugliflozin, as expected by its mechanism of action. The incidence of hypovolemia AEs, including hypotension, was low across the treatment groups (ertugliflozin and placebo).

A strength of the analysis is that the very similar design and endpoints of the three primary studies enabled data to be pooled, providing a larger number of patients than in any individual study and enabling an analysis of ertugliflozin efficacy in a variety of patient subgroups. Limitations include the post hoc exploratory nature of the analysis, which meant that no hypothesis testing was planned or performed, the relatively low number of patients on a diuretic, with renal impairment $\left(\right.$ eGFR $\left.<60 \mathrm{~mL} / \mathrm{min} / 1.73 \mathrm{~m}^{2}\right)$, and the enrollment of a small number of Black patients. In addition, adjustments for changes to dosing of concomitant antihypertensive therapies were not included in the analysis.

\section{Conclusion}

In conclusion, treatment with ertugliflozin $5 \mathrm{mg}$ and $15 \mathrm{mg}$ over 26 weeks was well tolerated and resulted in reductions in SBP, DBP, pulse pressure, mean arterial pressure, and double product relative to placebo. The SBP effect was consistent across patient subgroups and reductions in BP were achieved without an increase in pulse rate.

Table 4 Summary of overall safety and orthostatic blood pressure changes

\begin{tabular}{|c|c|c|c|}
\hline & $\begin{array}{l}\text { Placebo } \\
(n=515)\end{array}$ & $\begin{array}{l}\text { Ertugliflozin } 5 \mathrm{mg} \\
(\mathrm{n}=519)\end{array}$ & $\begin{array}{l}\text { Ertugliflozin } 15 \mathrm{mg} \\
(\mathrm{n}=510)\end{array}$ \\
\hline Any AE & $263(51.1)$ & $236(45.5)$ & $257(50.4)$ \\
\hline Serious AE & $15(2.9)$ & $17(3.3)$ & $12(2.4)$ \\
\hline Discontinuation due to $\mathrm{AE}^{\mathrm{a}}$ & $9(1.7)$ & $12(2.3)$ & $7(1.4)$ \\
\hline Hypovolemia & $9(1.7)$ & $4(0.8)$ & $5(1.0)$ \\
\hline Osmotic diuresis & $5(1.0)$ & $15(2.9)$ & $12(2.4)$ \\
\hline \multicolumn{4}{|l|}{ Orthostatic change in SBP } \\
\hline Baseline, n/m (\%) & $14 / 502(2.8)$ & $21 / 516(4.1)$ & 16/494 (3.2) \\
\hline Week 6, n/m (\%) & 16/477 (3.4) & 16/493 (3.2) & 17/476 (3.6) \\
\hline Week 26, n/m (\%) & $18 / 446(4.0)$ & 16/475 (3.4) & $17 / 458(3.7)$ \\
\hline \multicolumn{4}{|l|}{ Orthostatic change in DBP } \\
\hline Baseline, n/m (\%) & $72 / 502(14.3)$ & $80 / 516(15.5)$ & $81 / 494(16.4)$ \\
\hline Week 6, n/m (\%) & $74 / 477(15.5)$ & $81 / 493(16.4)$ & $68 / 476(14.3)$ \\
\hline Week 26, n/m (\%) & $65 / 446(14.6)$ & $82 / 475$ (17.3) & $75 / 458(16.4)$ \\
\hline
\end{tabular}

Data presented as number of patients (\%). $n$ is the number of patients with test results at that visit that met the predetermined criterion; $m$ is the number of patients with at least one test result at that visit

$A E$ adverse event, $D B P$ diastolic blood pressure, SBP systolic blood pressure

a Study medication withdrawn 


\section{Additional file}

Additional file 1. List of MedDRA preferred terms for diabetic microvascular complications

\section{Publisher's Note}

Springer Nature remains neutral with regard to jurisdictional claims in published maps and institutional affiliations.

Received: 22 January 2019 Accepted: 8 April 2019

Published online: 07 May 2019

\section{References}

1. American Diabetes Association. Cardiovascular disease and risk management: standards of medical care in diabetes-2018. Diabetes Care. 2018:41:586-104.

2. de Boer $\mathrm{H}$, Bangalore $\mathrm{S}$, Benetos $\mathrm{A}$, Davis AM, Michos ED, Muntner $\mathrm{P}$, Rossing P, Zoungas S, Bakris G. Diabetes and hypertension: a position statement by the American Diabetes Association. Diabetes Care. 2017:40:1273-84.

3. Whelton PK, Carey RM, Aronow WS, Casey DE, Collins KJ, Dennison Himmelfarb C, DePalma SM, Gidding S, Jamerson KA, Jones DW, et al. 2017 ACC/AHA/AAPA/ABC/ACPM/AGS/APhA/ASH/ASPC/NMA/PCNA Guideline for the prevention, detection, evaluation, and management of high blood pressure in adults: a report of the American College of Cardiology/ American Heart Association Task Force on clinical practice guidelines. J Am Coll Cardiol. 2018:71:e127-248.

4. Davies MJ, D'Alessio DA, Fradkin J, Kernan WN, Mathieu C, Mingrone G, Rossing P, Tsapas A, Wexler DJ, Buse JB. Management of hyperglycemia in type 2 diabetes, 2018. A consensus report by the American Diabetes Association (ADA) and the European Association for the Study of Diabetes (EASD). Diabetes Care. 2018;41:2669-701.

5. Williams B, Mancia G, Spiering W, Agabiti Rosei E, Azizi M, Burnier M, Clement DL, Coca A, de Simone G, Dominiczak A, et al. 2018 ESC/ESH Guidelines for the management of arterial hypertension. Can J Diabetes. 2018;39:3021-104

6. Lesniak W, Bala MM, Placzkiewicz-Jankowska E, Topor-Madry R, Jankowski $\mathrm{M}$, Sieradzki J, Banasiak W. Cardiovascular risk management in type 2 diabetes of more than 10-year duration: results of Polish ARETAEUS2-Grupa Study. Cardiol J. 2015;22:150-9.

7. Stark Casagrande S, Fradkin JE, Saydah SH, Rust KF, Cowie CC. The prevalence of meeting A1C, blood pressure, and LDL goals among people with diabetes, 1988-2010. Diabetes Care. 2013;36:2271-9.

8. Vouri SM, Shaw RF, Waterbury NV, Egge JA, Alexander B. Prevalence of achievement of $A 1 C$, blood pressure, and cholesterol (ABC) goal in veterans with diabetes. J Manag Care Pharm. 2011;17:304-12.

9. Nelson SA, Dresser GK, Vandervoort MK, Wong CJ, Feagan BG, Mahon JL, Feldman RD. Barriers to blood pressure control: a STITCH substudy. J Clin Hypertens (Greenwich). 2011;13:73-80.

10. Briasoulis A, Al Dhaybi O, Bakris GL. SGLT2 inhibitors and mechanisms of hypertension. Curr Cardiol Rep. 2018;20:1.

11. Pfeifer M, Townsend RR, Davies MJ, Vijapurkar U, Ren J. Effects of canagliflozin, a sodium glucose co-transporter 2 inhibitor, on blood pressure and markers of arterial stiffness in patients with type 2 diabetes mellitus: a post hoc analysis. Cardiovasc Diabetol. 2017;16:29.

12. Cherney DZI, Cooper ME, Tikkanen I, Pfarr E, Johansen OE, Woerle HJ, BroedI UC, Lund SS. Pooled analysis of Phase III trials indicate contrasting influences of renal function on blood pressure, body weight, and $\mathrm{HbA} 1 \mathrm{C}$ reductions with empagliflozin. Kidney Int. 2018;93:231-44.

13. Mancia G, Cannon CP, Tikkanen I, Zeller C, Ley L, Woerle HJ, Broedl UC, Johansen OE. Impact of empagliflozin on blood pressure in patients with type 2 diabetes mellitus and hypertension by background antihypertensive medication. Hypertension. 2016;68:1355-64.

14. Zinman B, Wanner C, Lachin JM, Fitchett D, Bluhmki E, Hantel S, Mattheus M, Devins T, Johansen OE, Woerle HJ, et al. Empagliflozin, cardiovascular outcomes, and mortality in type 2 diabetes. N Engl J Med. 2015;373:2117-28.

15. Neal B, Perkovic V, Mahaffey KW, de Zeeuw D, Fulcher G, Erondu N, Shaw W, Law G, Desai M, Matthews DR. Canagliflozin and cardiovascular and renal events in type 2 diabetes. N Engl J Med. 2017;377:644-57.

16. Inzucchi SE, Zinman B, Fitchett D, Wanner C, Ferrannini E, Schumacher M, Schmoor C, Ohneberg K, Johansen OE, George JT, et al. How does
This study was funded by Merck Sharp \& Dohme Corp., a subsidiary of Merck \& Co., Inc., Kenilworth, NJ, USA, in collaboration with Pfizer Inc. 
empagliflozin reduce cardiovascular mortality? Insights from a mediation analysis of the EMPA-REG OUTCOME trial. Diabetes Care. 2018;41:356-63.

17. Mudaliar S, Alloju S, Henry RR. Can a shift in fuel energetics explain the beneficial cardiorenal outcomes in the EMPA-REG OUTCOME study? A unifying hypothesis. Diabetes Care. 2016:39:1115-22.

18. Wiviott SD, Raz I, Bonaca MP, Mosenzon O, Kato ET, Cahn A, Silverman MG, Zelniker TA, Kuder JF, Murphy SA, et al. Dapagliflozin and cardiovascular outcomes in type 2 diabetes. N Engl J Med. 2019;24:347-57.

19. Rosenstock J, Frias J, Pall D, Charbonnel B, Pascu R, Saur D, Darekar A Huyck S, Shi H, Lauring B, et al. Effect of ertugliflozin on glucose control, body weight, blood pressure and bone density in type 2 diabetes mellitus inadequately controlled on metformin monotherapy (VERTIS MET). Diabetes Obes Metab. 2018;20:520-9.

20. Dagogo-Jack S, Liu J, Eldor R, Amorin G, Johnson J, Hille D, Liao Y, Huyck S, Golm G, Terra SG, et al. Efficacy and safety of the addition of ertugliflozin in patients with type 2 diabetes mellitus inadequately controlled with metformin and sitagliptin: the VERTIS SITA2 placebo-controlled randomized study. Diabetes Obes Metab. 2018;20:530-40.

21. Pratley RE, Eldor R, Raji A, Golm G, Huyck SB, Qiu Y, Sunga S, Johnson J, Terra SG, Mancuso JP, et al. Ertugliflozin plus sitagliptin versus either individual agent over 52 weeks in patients with type 2 diabetes mellitus inadequately controlled with metformin: the VERTIS FACTORIAL randomized trial. Diabetes Obes Metab. 2018;20:1111-20.

22. Miller S, Krumins T, Zhou H, Huyck S, Johnson J, Golm G, Terra SG, Mancuso JP, Engel SS, Lauring B. Ertugliflozin and sitagliptin co-initiation in patients with type 2 diabetes: the VERTIS SITA randomized study. Diabetes Ther. 2018;9:253-68.

23. Terra SG, Focht K, Davies M, Frias J, Derosa G, Darekar A, Golm G, Johnson J, Saur D, Lauring B, et al. Phase III, efficacy and safety study of ertugliflozin monotherapy in people with type 2 diabetes mellitus inadequately controlled with diet and exercise alone. Diabetes Obes Metab. 2017;19:721-8.

24. American Diabetes Association. Executive summary: standards of medical care in diabetes-2012. Diabetes Care. 2012;35(Suppl 1):S4-10.

25. Liang K-Y, Zeger SL. Longitudinal data analysis of continuous and discrete responses for pre-post designs. Sankhyā. 2000;62:134-48.

26. Miettinen $\mathrm{O}$, Nurminen M. Comparative analysis of two rates. Stat Med. 1985:4:213-26

27. Weber MA, Mansfield TA, Cain VA, lqbal N, Parikh S, Ptaszynska A. Blood pressure and glycaemic effects of dapagliflozin versus placebo in patients with type 2 diabetes on combination antihypertensive therapy: a randomised, double-blind, placebo-controlled, phase 3 study. Lancet Diabetes Endocrinol. 2016;4:211-20.

28. Weber MA, Mansfield TA, Alessi F, labal N, Parikh S, Ptaszynska A. Effects of dapagliflozin on blood pressure in hypertensive diabetic patients on renin-angiotensin system blockade. Blood Press. 2016;25:93-103.

29. Zaccardi F, Webb DR, Htike ZZ, Youssef D, Khunti K, Davies MJ. Efficacy and safety of sodium-glucose co-transporter-2 inhibitors in type 2 diabetes mellitus: systematic review and network meta-analysis. Diabetes Obes Metab. 2016;18:783-94.

30. Shyangdan DS, Uthman OA, Waugh N. SGLT-2 receptor inhibitors for treating patients with type 2 diabetes mellitus: a systematic review and network meta-analysis. BMJ Open. 2016;6:e009417.

31. Davies MJ, Merton K, Vijapurkar U, Yee J, Qiu R. Efficacy and safety of canagliflozin in patients with type 2 diabetes based on history of cardiovascular disease or cardiovascular risk factors: a post hoc analysis of pooled data. Cardiovasc Diabetol. 2017;16:40.

32. Gallo S, Charbonnel B, Goldman A, Shi H, Huyck S, Darekar A, Lauring B, Terra SG. Long-term efficacy and safety of ertugliflozin in patients with type 2 diabetes mellitus inadequately controlled with metformin monotherapy: 104-week VERTIS MET trial. Diabetes Obes Metab. 2019. https:// doi.org/10.1111/dom.13631.
33. Mazidi M, Rezaie P, Gao HK, Kengne AP. Effect of sodium-glucose cotransport-2 inhibitors on blood pressure in people with type 2 diabetes mellitus: a systematic review and meta-analysis of 43 randomized control trials with 22528 patients. J Am Heart Assoc. 2017;6:e004007.

34. Hollander P, Liu J, Hill J, Johnson J, Jiang ZW, Golm G, Huyck S, Terra SG, Mancuso JP, Engel SS, et al. Ertugliflozin compared with glimepiride in patients with type 2 diabetes mellitus inadequately controlled on metformin: the VERTIS SU randomized study. Diabetes Ther. 2018;9:193-207.

35. Amin NB, Wang X, Mitchell JR, Lee DS, Nucci G, Rusnak JM. Blood pressure-lowering effect of the sodium glucose co-transporter-2 inhibitor ertugliflozin, assessed via ambulatory blood pressure monitoring in patients with type 2 diabetes and hypertension. Diabetes Obes Metab. 2015;17:805-8

36. Baker WL, Buckley LF, Kelly MS, Bucheit JD, Parod ED, Brown R, Carbone S, Abbate A, Dixon DL. Effects of sodium-glucose cotransporter 2 inhibitors on 24-hour ambulatory blood pressure: a systematic review and metaanalysis. J Am Heart Assoc. 2017;6:e005686.

37. Kawasoe S, Maruguchi Y, Kajiya S, Uenomachi H, Miyata M, Kawasoe M, Kubozono T, Ohishi M. Mechanism of the blood pressure-lowering effect of sodium-glucose cotransporter 2 inhibitors in obese patients with type 2 diabetes. BMC Pharmacol Toxicol. 2017;18:23.

38. Petersen KS, Blanch N, Keogh JB, Clifton PM. Effect of weight loss on pulse wave velocity: systematic review and meta-analysis. Arterioscler Thromb Vasc Biol. 2015;35:243-52

39. Aroor AR, Das NA, Carpenter AJ, Habibi J, Jia G, Ramirez-Perez Fl, Martinez-Lemus L, Manrique-Acevedo CM, Hayden MR, Duta C, et al. Glycemic control by the SGLT2 inhibitor empagliflozin decreases aortic stiffness, renal resistivity index and kidney injury. Cardiovasc Diabetol. 2018;17:108.

40. Chilton R, Tikkanen I, Cannon CP, Crowe S, Woerle HJ, Broedl UC, Johansen OE. Effects of empagliflozin on blood pressure and markers of arterial stiffness and vascular resistance in patients with type 2 diabetes. Diabetes Obes Metab. 2015;17:1180-93.

41. Cockcroft JR, Wilkinson IB, Evans M, McEwan P, Peters JR, Davies S, ScanIon MF, Currie CJ. Pulse pressure predicts cardiovascular risk in patients with type 2 diabetes mellitus. Am J Hypertens. 2005;18:1463-7 (discussion 1468-1469).

42. Rawshani A, Rawshani A, Franzen S, Sattar N, Eliasson B, Svensson AM, Zethelius B, Miftaraj M, McGuire DK, Rosengren A, et al. Risk factors, mortality, and cardiovascular outcomes in patients with type 2 diabetes. N Engl J Med. 2018;379:633-44.

43. Cannon CP, McGuire DK, Pratley R, Dagogo-Jack S, Mancuso J, Huyck S, Charbonnel B, Shih WJ, Gallo S, Masiukiewicz U, et al. Design and baseline characteristics of the eValuation of ERTugliflozin efflcacy and Safety CardioVascular outcomes trial (VERTIS-CV). Am Heart J. 2018;206:11-23.

44. Cefalu WT, Leiter LA, de Bruin TW, Gause-Nilsson I, Sugg J, Parikh SJ. Dapagliflozin's effects on glycemia and cardiovascular risk factors in highrisk patients with type 2 diabetes: a 24-week, multicenter, randomized, double-blind, placebo-controlled study with a 28-week extension. Diabetes Care. 2015;38:1218-27.

45. Reed JW. Impact of sodium-glucose cotransporter 2 inhibitors on blood pressure. Vasc Health Risk Manag. 2016;12:393-405.

46. Fleg JL, Evans GW, Margolis KL, Barzilay J, Basile JN, Bigger JT, Cutler JA, Grimm R, Pedley C, Peterson K, et al. Orthostatic hypotension in the ACCORD (Action to Control Cardiovascular Risk in Diabetes) blood pressure trial: prevalence, incidence, and prognostic significance. Hypertension. 2016;68:888-95. 